\title{
Estimation of suspended sediment concentrations with ADCP in Danube River
}

\author{
Sándor Baranya *, János Józsa \\ Water Management Research Group of the Hungarian Academy of Sciences, Department of Hydraulic and Water Resources Engineering, \\ Budapest University of Technology and Economics, Muegyetem rkp. 3, H-1111, Budapest, Hungary. \\ *Corresponding author: E-mail: baranya@vit.bme.hu
}

\begin{abstract}
An estimation procedure for suspended sediment concentrations based on the intensity of backscattered sound of acoustic Doppler current profilers (ADCP) is introduced in this paper. Based on detailed moving and fixed boat ADCP measurements with concurrent sediment sampling, we have successfully calibrated the estimation method for a reach of River Danube in Hungary, characterized by significant suspended sediment transport. The effect of measurement uncertainty and various data filtering on sediment load determination is also analyzed and quantified. Some of the physical model parameters describing the propagation of sound in water are estimated based on known empirical formulas, while other parameters are derived from measured. Regression analysis is used to obtain a relationship between the intensity of backscattered sound and sediment concentrations. The empirical relationship has been then used to estimate the suspended sediment concentrations from the ADCP data collected in fixed and moving boat measurement operation mode, along verticals and path-lines, respectively. We show that while some measurement uncertainty is inherent to the acoustic Doppler principle, it is further enhanced by the complexity of the near-bottom sediment-laden flow. This uncertainty has then a significant effect on the local sediment load estimation. In turn, reasonable smoothing of raw velocity and backscatter intensity data shows insignificant impact on cross-sectional sediment load estimation.
\end{abstract}

Keywords: Suspended sediment concentration; ADCP; Danube.

\section{INTRODUCTION}

The main application field of acoustic Doppler current profilers (ADCPs) is the measurement of flow velocities in order to determine river discharge. However, as an additional option of these tools the intensity of backscattered sound can be used to indicate sediment characteristics in the water. In the last decade, a few papers were published on this topic analyzing the potential in suspended sediment concentration (SSC) estimations, mainly in coastal applications. In riverine environment, one of the first attempts was published by Reichel and Nachtnebel (1994), who studied the advantages and limitations of using ADCP for suspended sediment monitoring. They pointed out that using single-frequency ADCPs changes in backscatter intensity can be associated both with changes in sediment size and concentration, thus, causes uncertainty in case of poorly sorted particle sizes. Gartner (2004) used an optical backscatter sensor (OBS) to compare SSC from ADCP measurements in San Francisco Bay, California. He introduced good agreement between the two methods, however, marked a slight difference near to bottom. Gartner (2004) commented on the dependence of backscatter intensity from particle sizes, stating that the method requires a reasonably steady size distribution of suspended material. The authors further noted that errors associated with the OBS calibrations can affect the quality of acoustic estimates. Kostaschuk et al. (2005) used an ADCP to study flow velocity and sediment transport in Fraser Estuary and Lillooet Lake in western Canada. Besides conventional velocity measurements, bottom track data were used to examine bed load velocity, however, more research is required to see if this method can be used for detailed studies of geophysical flows. For the estimation of suspended sediment concentrations, pump samples were compared with ADCP backscatter data, showing a fairly strong correlation. Kim and Voulgaris (2003) estimated $S S C$ in an estuarine environment comparing ADCP and OBS data. They presented a methodology by which through calibration and verification processes a suitable equation could be developed to estimate suspended sediment concentrations. Guerrero et al. (2011) used a multi-frequency method with two ADCPs $(600 \mathrm{kHz}$ and $1200 \mathrm{kHz}$ Teledyne RD Instruments ADCP) to study suspended sediment concentrations and grain size distributions in River Paraná. Their field measurements were compared with data obtained by a previously calibrated $1000 \mathrm{kHz}$ Sontek ADCP. This was the first attempt to characterize the concentration and grain size distribution in a large river and pointed out important relationships between these two characteristics. As a continuation of the previous work Guerrero et al. (2012) carried out laboratory tests with the twofrequency method for grain size assessment using two ADCPs. They observed good agreement between the known and ADCPs-inferred grain size distributions within 100-600 $\mu \mathrm{m}$.

The objective of this paper is twofold. First, we investigate the feasibility of SSC determination with ADCP through a real case study. A relatively fast procedure is introduced, which could be later implemented into operational monitoring activities. The main goal is to see the practical applicability of the herein introduce method. Second, we perform a sensitivity analysis to show how the ADCP data uncertainty in the nearbed zone and close to the free surface influences the suspended sediment load estimation. The study site is a reach located within the Hungarian section of the Danube. Engineering works are planned here to maintain fluvial navigational channels. Therefore, numerical modeling of hydrodynamics and morphological changes were carried out to predict the effect of the designed structures on river bed changes. The herein presented ADCP measurements and sediment data collection were performed for model parameterization purposes. 


\section{THEORETICAL BACKGROUND}

In contrast with flow velocity measurements, where the frequency of backscattered sound is postprocessed to determine three-dimensional velocity data, here we analyze the strength of the reverberated sound. The relationship between SSC and the so-called relative acoustic backscatter $(R B)$ can be expressed as (e.g. Gartner, 2004):

$$
S S C=10^{(A+B \cdot R B)} .
$$

The relative backscatter is the measured acoustic backscatter corrected for transmission losses in units of $\mathrm{dB}$. Following Thevenot et al. (1992) the $R B$ can be derived from

$R B=R L+2 \cdot T L$,

where $R L$ is the reverberation level and $2 \cdot T L$ is the two-way transmission loss, both expressed in dB. $A$ and $B$ in Eq. (1) are empirical parameters that can be derived from known SSC and $R B$ data pairs using e.g. least squares fitting.

Based on the sonar equation (Urick, 1983) the reverberation level $(R L)$ is

$R L=S L-2 \cdot T L+T S$,

where $S L$ is the source level (the sonar transmits the signal with this strength), whereas $T S$ is the target strength of suspended sediment, which is a function of particle shape, size, rigidity, and acoustic wavelength. In the sonar equation all terms are in $\mathrm{dB}$. When measuring with an ADCP the reverberation level comes from

$$
R L=K_{c}\left(E I-E_{r}\right),
$$

where $K_{c}$ is the received signal strength indicator scale factor, $E I$ is the echo strength (in counts) measured by the ADCP and $E_{r}$ is the reference level for echo intensity (in counts), i.e. the echo baseline value when no signal is present. $K_{c}$ is a conversion factor from instrument counts to echo intensity which is instrument-specific and temperature dependent (DRL Software Ltd, 2003). It can be estimated using the following formula:

$$
K_{c}=\frac{127.3}{T_{e}+127.3},
$$

where $T_{e}$ is the real-time temperature of the amplification circuits in ${ }^{\circ} \mathrm{C}$. It generally has a value between $0.35-0.55$ (Deines, 1999). The ADCP reference level $E_{r}$ is the thermal noise of the amplifiers, which is transducer-specific as well as sensitive to temperature (DRL Software Ltd, 2003) and can be measured in the field. The term 'transmission loss' consists of losses accounted for by spherical spreading of the beam (first term on the right side) and losses due to absorption (second term):

$$
T L=10 \cdot \psi \cdot \log (R)+\alpha \cdot R,
$$

where $R$ is the slant range from transducer head to measured bin (m), while $\alpha$ is a coefficient describing the absorption of energy by water $\left(\alpha_{w}\right)$ and attenuation from suspended sediments $\left(\alpha_{s}\right)$, i.e. $\alpha=\alpha_{\mathrm{W}}+\alpha_{\mathrm{s}}$ (all in $\left.\mathrm{dB} / \mathrm{m}\right)$. When calculating the effect of spherical spreading close to the transducer, a near-field correction factor $\psi$ has to be introduced, according to Downing et al. (1995). This correction can be calculated based on the so called critical range $R_{\text {critical }}$, where $R_{\text {critical }}=\pi a_{t}^{2} / \lambda$. Here $a_{t}$ is the transducer radius in $\mathrm{cm}$, and $\lambda$ is the acoustic wavelength. The correction factor for near-field spreading loss is:

$\psi=\frac{\left[1+1.35 Z+(2.5 Z)^{3.2}\right]}{\left[1.35 Z+(2.5 Z)^{3.2}\right]}$,

where $Z$ equals to $R / R_{\text {critical. }}$ In this study the above presented correction factor was used for near-field calculations of spreading losses. For the estimation of energy dissipation by absorption in the water we used the formula of Schulkin and Marsh (1962) as follows:

$\alpha_{w}=8.687 \frac{3.38 \cdot 10^{-6} \cdot f^{2}}{f_{T}}$,

where $f$ is the instrument frequency $(\mathrm{Hz})$ and $f_{T}$ is the so called Relaxation Frequency $(\mathrm{Hz})$. The latter depends on the water temperature, $T\left({ }^{\circ} \mathrm{C}\right)$ as:

$f_{T}=21.9 \cdot 10^{\left(6-\frac{1520}{273+T}\right)}$.

Attenuation from suspended sediment $\left(\alpha_{s}\right)$ is caused by both scattering and absorbing the energy. It is shown that energy dissipation depends mainly on particle size and sound frequency (DRL Software Ltd, 2003), and under certain conditions one or both of them can be neglected. We did not consider attenuation due to absorption by the sediment here, as discussed later on.

Substituting the above detailed terms into Eq. (1) the following relation can be written:

$S S C=10^{A+B \cdot\left(K_{C}(E I-E r)+2(10 \cdot \log (R)+\alpha \cdot R)\right)}$.

Here, echo intensity $(E I)$, slant distance $(R)$ and reference level $\left(E_{r}\right)$ can be measured with ADCP, $K_{c}$ and $\alpha$ are estimated, whereas $A$ and $B$ parameters can be derived with e.g. least squares fitting, if complementary SSC data are available.

\section{STUDY SITE AND FIELD SURVEYS}

To test the feasibility of backscatter-based SSC estimation, a six $\mathrm{km}$ long reach of Danube River was chosen, situated in the southernmost part of Hungary, downstream of the town of Mohács (Fig. 1). In contrast with the North- and CentralHungarian section of the Danube where gravel and sand-gravel bed material dominates, in the study reach sand bed conditions prevail. Based on the data series of suspended sediment concentrations measured and provided by the Lower-Danube-Valley Environmental and Water Directorate, the average suspended sediment concentration is approximately $40 \mathrm{mg} / \mathrm{l}$ (Tamás and Baranya, 2008). Typical suspended sediment grain diameter ranges from $0.01 \mathrm{~mm}$ to $0.1 \mathrm{~mm}$ in the studied river reach.

An intensive measurement campaign was carried out in quasi-steady state conditions between low and mean flow regime with a discharge of $1950 \mathrm{~m}^{3} / \mathrm{s}$. The survey was done in seven cross-sections with an average spacing of 600 meters apart, in moving boat operation. Additionally, within each transect five points were defined where fixed boat measurements were taken 


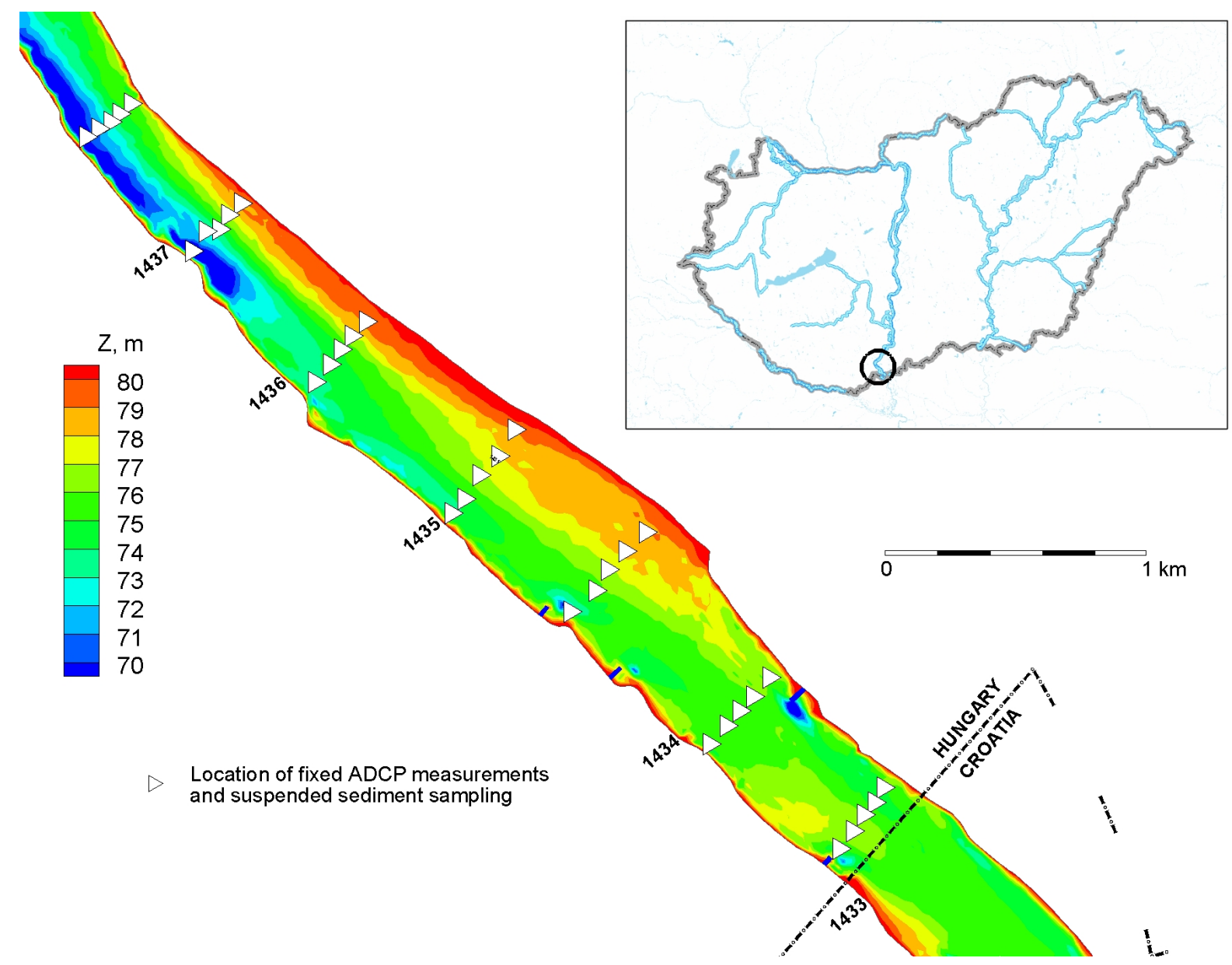

Fig. 1. Plan view of the studied river reach.

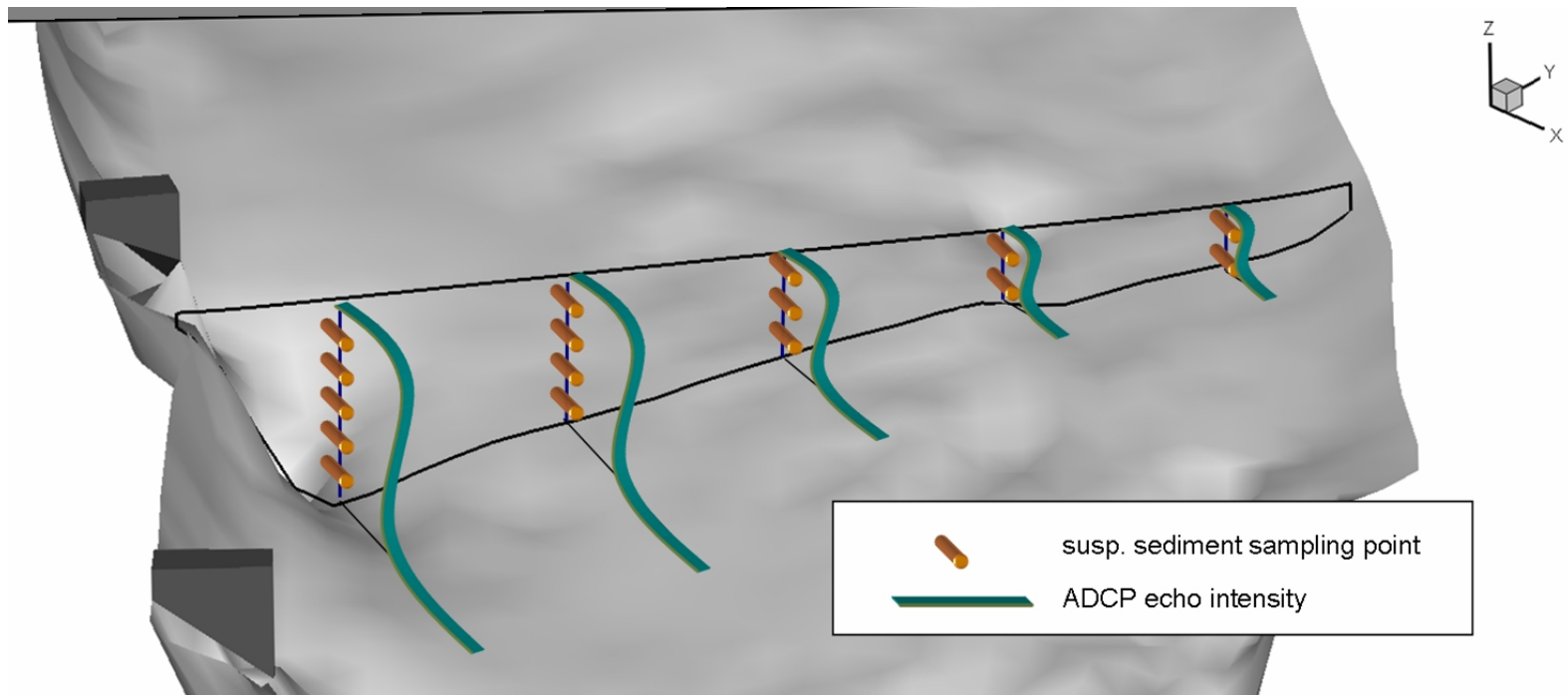

Fig. 2. Sketch of sampling point distribution and typical echo intensity profile in a cross-section.

with 10 minutes long sampling time (Fig. 2). The applied device was an RDI four beam $600 \mathrm{kHz}$ Rio Grande ADCP deployed from a vessel. Measurements were carried out with 2.5 $\mathrm{Hz}$ sampling frequency with $50 \mathrm{~cm}$ bin size. During the survey DGPS position data were continuously collected, thus each measurement was located in an absolute coordinate system.

In order to provide measured data for the calibration of the above introduced method, suspended sediment sampling was simultaneously carried out using a pump. Water samples were taken from different depths of the water column (2-5 samples per profile) in 35 profiles in all (identical with the ones measured with fixed ADCP). Laboratory analysis of the samples provided concentrations for each measurement point and grain size distributions for each profile. The distribution of the sampling points in a cross-section is shown in Fig. 2. 


\section{CONVERSION OF ADCP BACKSCATTER DATA TO SSC}

Raw echo intensity data $(E I)$ measured by ADCP were postprocessed to estimate SSC. First, the reference level for echo intensity $\left(E_{r}\right)$ had to be defined. Due to the lack of laboratory tests, field data were used for determination of $E_{r}$, taking the lowest intensity data from the measurements ( $E_{r}=55$ counts). Second, the conversion factor, $K_{c}$ was estimated using Eq. (5), which resulted in a value of 0.43 . Third, $\alpha_{w}$ and $\alpha_{s}$ were estimated. Based on Eq. (8) we estimated the water absorption coefficient, resulting in a value of 0.1 . Attenuation due to sediment can be divided in to parts: absorption and scattering. As was illustrated by DRL Software Ltd (2003) in case of a 600 $\mathrm{kHz} \mathrm{ADCP}$, attenuation due to absorption by sediment can play a role only below a particle diameter of $200 \mu \mathrm{m}$. On the contrary, the same instrument is insensitive to scattering by the sediment up to $200 \mu \mathrm{m}$. In our case the laboratory analysis of suspended sediment samples pointed out a reasonably well sorted grain size distribution (Fig. 3) with $d_{50}$ equal to $35 \mu \mathrm{m}$. Therefore, the attenuation due to scattering could be neglected. The attenuation due to absorption resulted in $\alpha_{s}=0.0005 \mathrm{~dB} / \mathrm{m}$ for a concentration of $1 \mathrm{mg} / \mathrm{l}$ (see the graph on page 2.14 in DRL Software Ltd (2003)). This value was multiplied with the measured average suspended sediment concentration yielding an attenuation coefficient of 0.035 . Due to the well sorted grain size distribution the effects of diverse grain sizes in the introduced method (reported by Reichel and Nachtnebel, 1994) could be omitted. Then, the range of near field $\left(R_{\text {critical }}\right)$ was calculated yielding a distance of 3.2 meters, underlining the need for near-field correction of spreading losses considering the $5 \mathrm{~m}$ average depth of the river.

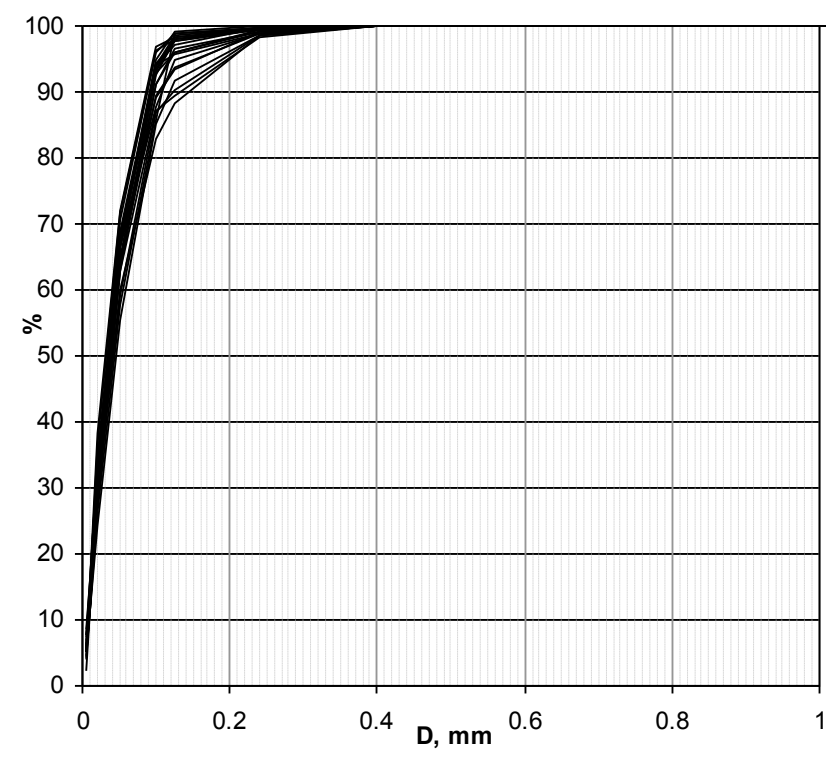

Fig. 3. Grain size distributions of sampled suspended sediment.

Next, we performed the following steps for all the fixed boat measurement verticals:

1) Generation of the 10-minute average echo intensity profiles.

2) Extracting the echo intensity values at the depths of pump samples, using a linear interpolation between the neighboring cells (see Fig. 2).

3) Calculation of slant ranges $(R)$ for all sampling points in the vertical.
4) Calculation of transmission losses by spherical spreading considering near-field correction for all sampling points in the vertical.

5) Calculation of transmission losses due to absorption by water and sediment for all sampling points in the vertical.

6) Calculation of relative backscatter values $(R B)$ by summing reverberation level $(R L)$ and transmission losses $(T L)$ for all sampling points in the vertical (see Eq. (2)).

In the field measurements we did not pay particular attention on sampling straight at the bottom thus a limited number of concentration data is available from this zone, only. In turn, their importance was then recognized during the data processing, supported by the fact that significant changes in the vertical concentration distribution were present mainly there. In order to cover as large range of concentration as possible, data from two cross-sections were processed, where suspended sediment samples were available also at the river bed. Having data pairs of relative backscatter $(R B)$ and measured suspended sediment concentration $\left(S S C_{\text {meas }}\right)$ a least squares fitting could be performed between $R B$ and $\log _{10}\left(S S C_{\text {meas }}\right)$, yielding the empirical parameter values $A=0.013$ and $B=-2.05$ with an acceptable fit of $\mathrm{R}^{2}=0.71$ (see Eq. (1)).

Based on the calibration parameters $A$ and $B$, the suspended sediment concentration profiles were reproduced for all the fixed ADCP verticals. Measured versus calculated concentrations show a fairly good agreement (Fig. 4), indicating an estimation error of $E=10 \mathrm{mg} / \mathrm{l}$ based on the following formula:

$E=\frac{\sum_{i=1}^{n}\left|S S C_{\text {meas }}-S S C_{A D C P}\right|}{n}$.

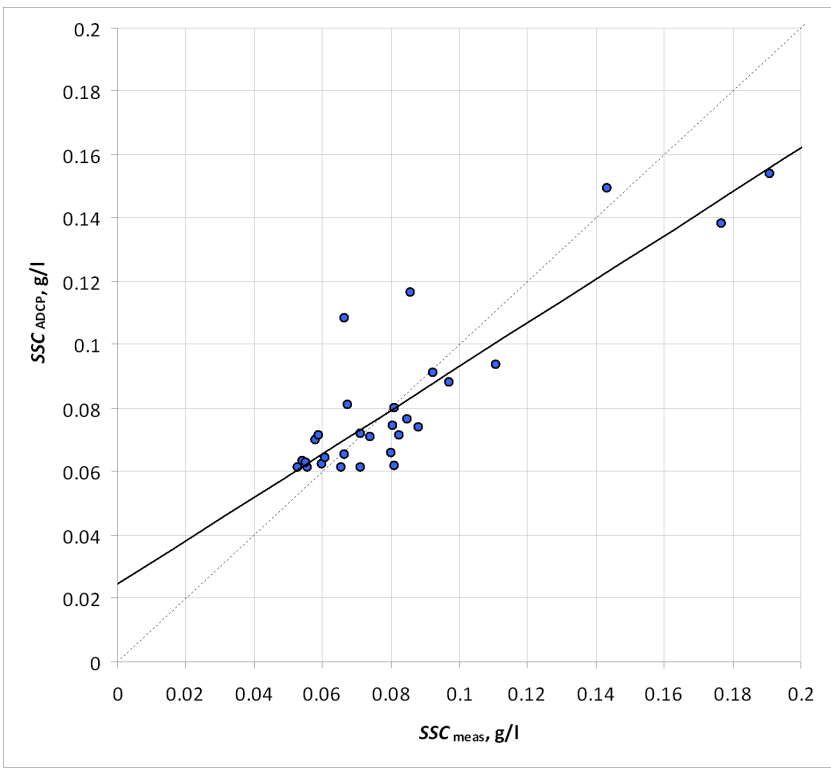

Fig. 4. SSC from field sampling versus estimated values from ADCP backscatter data (black line indicates the regression line fitted to the points).

As expected, a somewhat weaker relation comes up in the range of higher concentrations. This might be because of the operation mode of the ADCP. Since the four diverging beams sample larger areas nearing to bottom, where higher concentrations are observed, the deviation of backscatter intensities from the four beams becomes higher. This is even enhanced if sharp 
changes are present in the bed topography. Furthermore, the suspended sediment concentrations also affect the estimation method, since SSC is implicitly included in the formula, accounting for signal absorption by sediment (Urick, 1948). Fig. 5 shows SSC profiles for fixed ADCP verticals from one of the studied cross-sections. The estimated SSC values based on ADCP backscatter agree well with the ones from sampling. Note that estimated values are missing close to the free surface due to the ADCP blanking zone. Both the pump sampling results and the estimated values suggest a fairly uniform concentration distribution within the water column, whereas close to river bottom the sediment load significantly increases.

\section{ESTIMATION OF ERROR CAUSED BY MEASURE- MENT UNCERTAINTY AND DATA AVERAGING}

Uncertainty of echo intensity data becomes higher near the river bed, where higher sediment concentration arises. Furthermore, bed load can be present in this zone, moreover, irregularities in bed levels can further enhance inaccuracy in measurements. All these factors have an important role in sediment flux determination. At the same time, due to the so-called blanking zone of the ADCP no data are available close to the free surface, which might also influence the sediment load estimations. In order to see the effect of these error sources on the sediment flux estimations we performed a sensitivity analysis. A (reference) measurement vertical with typical water depth, velocity distribution and detected echo intensity (EI) distribution was chosen for the test. Based on the ADCP measurements reference profiles of time averaged velocity, EI, SSC and sediment flux were generated in subsequent steps. First, we fitted a logarithmic curve onto the measured time-averaged velocities in order to have extrapolated velocity values close to free surface and also at the river bed (Fig. 6a). Second, for the $E I$ profile, gradients in the upper- and lowermost measured layers were used to extrapolate values to the water surface and the river bed (Fig. 6b). Third, we converted the EI profile to $S S C$ using the above introduced calibration parameters, i.e. $A=$ 0.013 and $B=-2.05$ (Fig. 6c). Then, we calculated the sediment flux profile $\left(f_{S S}\right)$ as the product of $S S C$ and velocity (Fig. 6d). Finally, we calculated the depth-averaged suspended sediment flux $\left(F_{S S}\right)$ using the following formula:
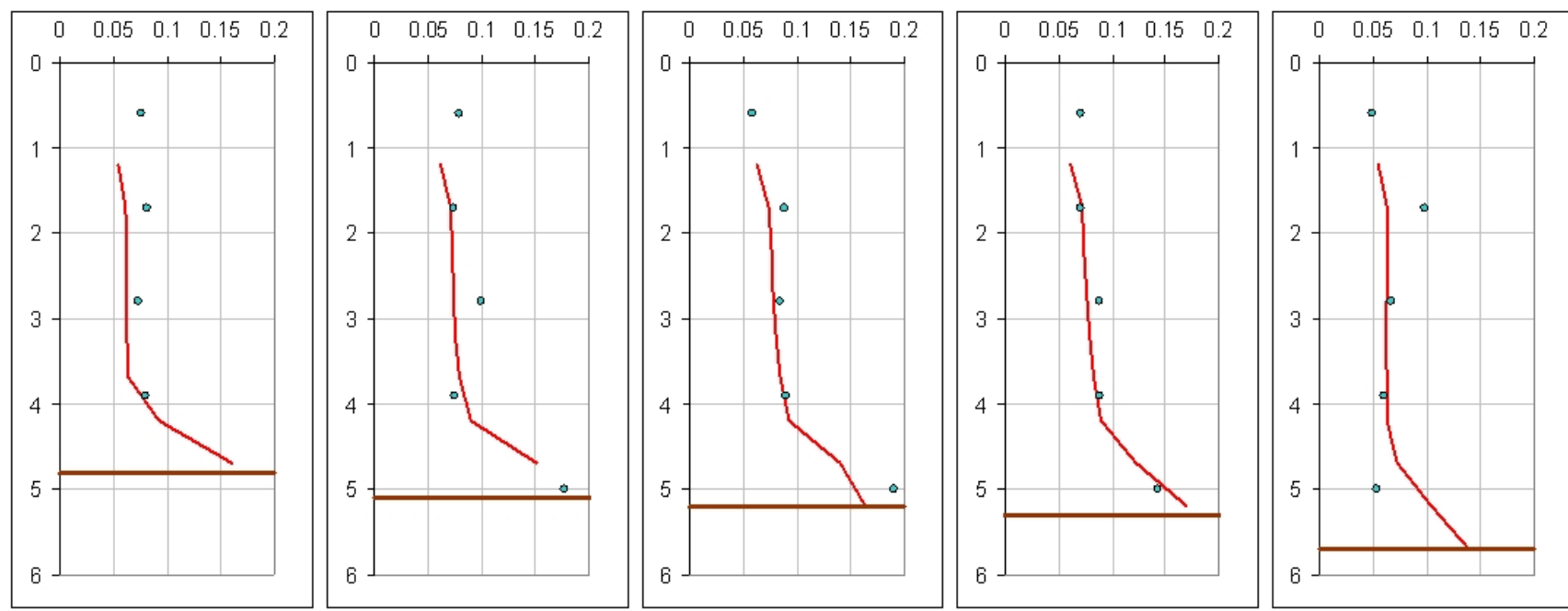

Fig. 5. Measured (dots) and estimated (lines) SSC profiles (horizontal-axis: SSC, g/l; vertical-axis: depth, m).
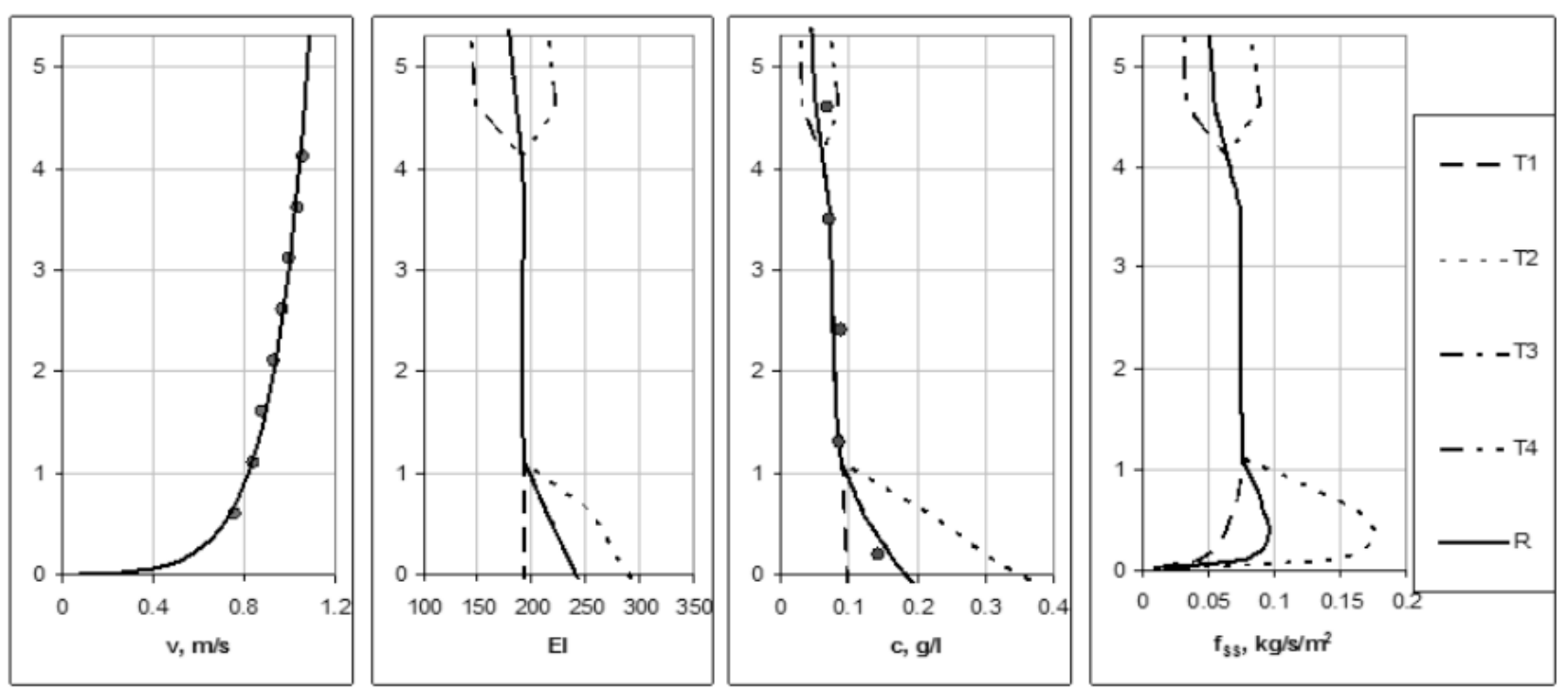

Fig. 6a) Time-averaged velocity profile; b) EI profile; c) SSC profile; d) Sediment flux profile. 


$$
F_{s s}=\frac{1}{H} \int_{0}^{H} c(z) \cdot v(z) d z
$$

The goal of the sensitivity analysis was to see how $F_{S S}$ changes if the reference $E I$ values change at the free surface and at the river bed. At the first step, we studied the effect of near-bottom echo intensity, assuming different profiles in the lowermost $1.2 \mathrm{~m}$ thick layer, where the accuracy of ADCP is known to be the poorest. In the first test variant (T1) we considered a constant $E I$ value towards the river bed. In the second test variant (T2) we increased the reference values by $20 \%$ (T2). Next, the reference $E I$ values in the uppermost 1.2 meter thick layer i.e. in the blanking zone of the ADCP were modified. Here, two more test variants were established: decreasing and increasing the $E I$ data by $20 \%$ (T3 and $\mathrm{T} 4$, respectively). The main test parameters and the influence on the sediment flux profile and $F_{S S}$ are provided in Table 1 as well as plotted in Fig. $6 \mathrm{~d}$. Summarizing the test results, we showed that an echo intensity estimation error of $20 \%$ at the river bed yields $16 \%$ change in the sediment flux, whereas at the free surface the same error in $E I$ causes a deviation of $8 \%$ from the reference value. It can also be seen that an underestimation of $E I$ generates slighter differences (variants T1 and T3), which clearly indicates the non-linearity in the relationship.

After calibrating the $S S C$ estimation procedure based on the fixed ADCP data, we extended the method to moving boat ADCP data. Here, we intended to calculate the section- integrated sediment load based on the instantaneous backscatter data. Due to the high sampling frequency of $2.5 \mathrm{~Hz}$ the instantaneous values show significant scattering both for velocity and echo intensity. Therefore a filtering of the raw data was performed, the influence of which on the sediment load estimation was also assessed.

Table 1. Test variants and results indicating the sensitivity of sediment flux to the variation of Echo Intensity.

\begin{tabular}{lccc}
\hline $\begin{array}{l}\text { Variant } \\
\text { name }\end{array}$ & $\begin{array}{c}\text { Modified } \\
\text { layer }\end{array}$ & Change & $\begin{array}{c}\text { Deviation from } \\
\text { Ref. in } F_{S S}\end{array}$ \\
\hline T1 & Lowest 20\% & Constant EI & $-6 \%$ \\
T2 & Lowest 20\% & Ref 1.2 & $+16 \%$ \\
T3 & Top 20\% & Ref $\cdot 0.8$ & $-5 \%$ \\
T4 & Top 20\% & Ref $\cdot 1.2$ & $+8 \%$ \\
\hline
\end{tabular}

For the analysis, we chose one of the surveyed crosssections and extracted raw velocity and $E I$ data. The previously discussed relationship between $E I$ and $S S C$ was applied, however, contrarily to time-averaged data, instantaneous $E I$ values were used. Since the reason of strong scattering cannot be unequivocally stated (turbulent motion, instrument noise, etc.), a horizontal filtering of the raw echo intensity data was performed using a moving average model with a window size of 5 , 9, 19 and 39 neighboring data. The $S S C$ values were then calculated based on the filtered $E I$ data (Fig. 7). Considering a con-

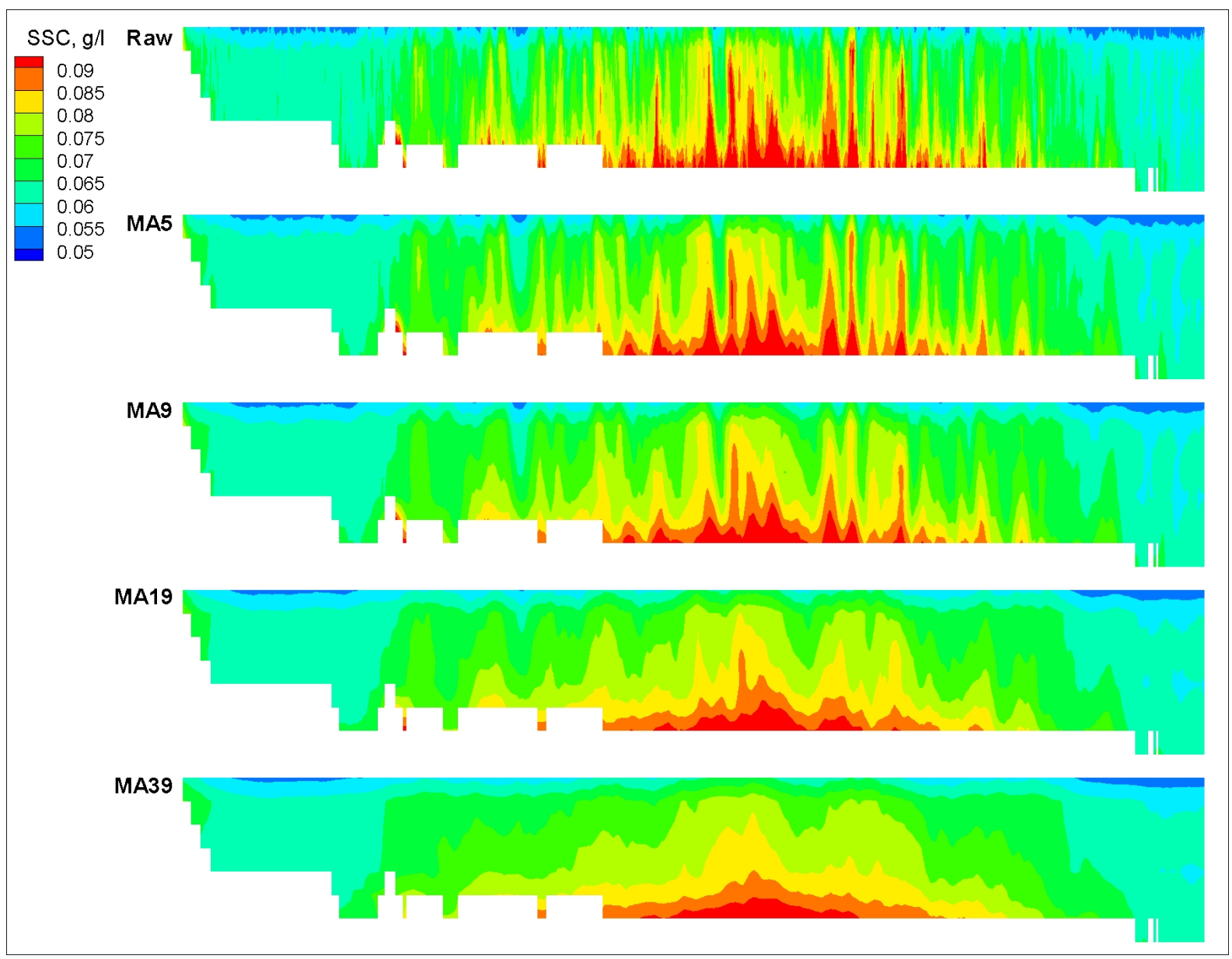

Fig. 7. $S S C$ estimation from moving boat ADCP backscatter data (MA indicates moving average window size). 


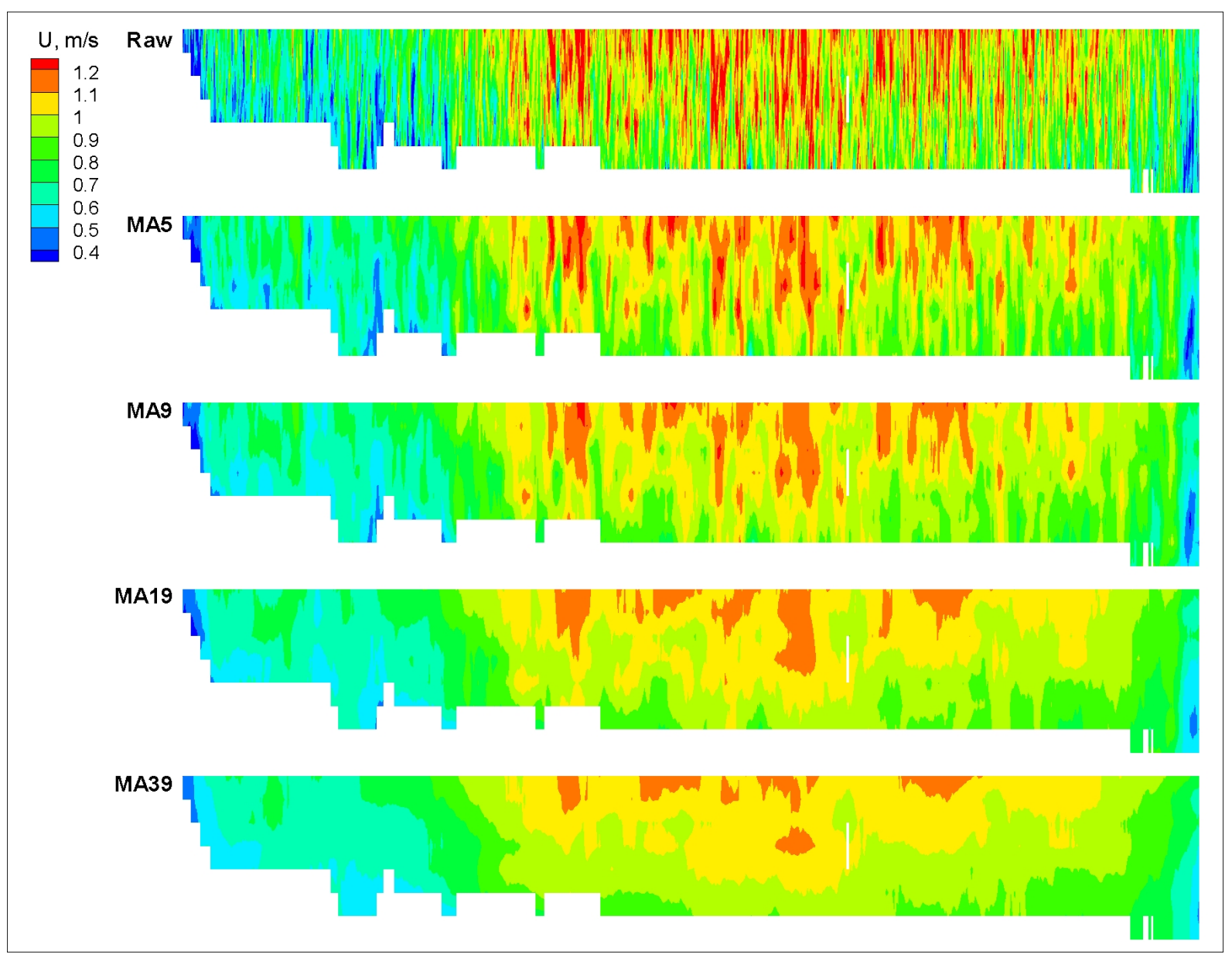

Fig. 8. Cross-sectional velocity distribution from ADCP measurement (MA indicates moving average window size).

stant boat speed of $1.35 \mathrm{~m} / \mathrm{s}$ and a sampling frequency of 2.5 $\mathrm{Hz}$ the applied data windows correspond to a spatial averaging of 2.7, 4.9, 10.3 and 21 meters, respectively. The same filtering process was applied to instantaneous velocity data in order to remove turbulent fluctuations from data series (Fig. 8). Next, the product of concentration and flow velocity was calculated for each bin resulting in the cross-sectional sediment flux distribution (Fig. 9). As can be seen in Fig. 9, data averaging offers a clear plot of the spatial changes of the variables, but at the same time it affects the suspended sediment load $\left(Q_{\mathrm{ss}}\right)$ determination. $Q_{\mathrm{SS}}$ was calculated by integrating the sediment flux over the measured cross-section. In order to see the effect of spatial and temporal data averaging on sediment discharge calculation, deviations from raw data were calculated and summarized in Table 2. To conclude, the section-integrated suspended sediment load estimation is not sensitive to averaging of $E I$ data, thus in case of an adequate calibration (e.g. based on fixed ADCP data) a stable $Q_{\mathrm{ss}}$ value can be obtained.

Table 2. Estimated sediment loads indicating the sensitivity of $Q_{\mathrm{sS}}$ to the variation of moving average window size.

\begin{tabular}{lcc}
\hline $\begin{array}{l}\text { MA } \\
\text { window }\end{array}$ & $\begin{array}{c}Q_{S S} \\
(\mathrm{~kg} / \mathrm{s})\end{array}$ & $\begin{array}{c}\text { Deviation } \\
\text { from raw data }\end{array}$ \\
\hline 0 & 75.77 & 0 \\
5 & 75.85 & $+0.11 \%$ \\
9 & 75.91 & $+0.18 \%$ \\
19 & 75.97 & $+0.26 \%$ \\
39 & 76.01 & $+0.32 \%$ \\
\hline
\end{tabular}

\section{SUMMARY AND CONCLUSIONS}

We introduced a method for converting ADCP echo intensity data into suspended sediment concentration through a case study. The study site was a reach of Danube River in Hungary. The reach has been recently investigated with detailed field measurements, including fixed as well as moving ADCP and suspended sediment sampling, to offer field data for numerical model parameterization. The SSC estimation method is based on a linear regression between the base-ten logarithm of measured $S S C$ (using a pump sampler) and the relative backscatter $(R B)$ derived from measured echo intensity $(E I)$ in the fixed ADCP mode. We found reasonable agreement between the measured and estimated SSC values showing an average estimation error of $10 \mathrm{mg} / \mathrm{l}$ (in a measured SSC range of 50-200 $\mathrm{mg} / \mathrm{l}$ ). In addition, we performed a sensitivity test to see how the unavoidable lack or inaccuracy of ADCP data near the free surface and the river bed influence the sediment load estimation, a major output of suspended sediment measurements. We showed that an error of $20 \%$ in the ADCP data can result in an error in the order of magnitude of $10 \%$ in the suspended sediment load estimation. Moving boat measurements were also post-processed to see the feasibility of section-integrated sediment load determination. Calibrated parameters from fixed boat ADCP data were used to convert $E I$ to $S S C$. Due to the strong scattering of the instantaneous EI data, the SSC also scatters and a smoothing of the data is needed for better interpretation of the cross-sectional distribution. It is a question, however, how the data filtering influences the suspended sediment load calculation. We showed that the sediment load estimation is not 


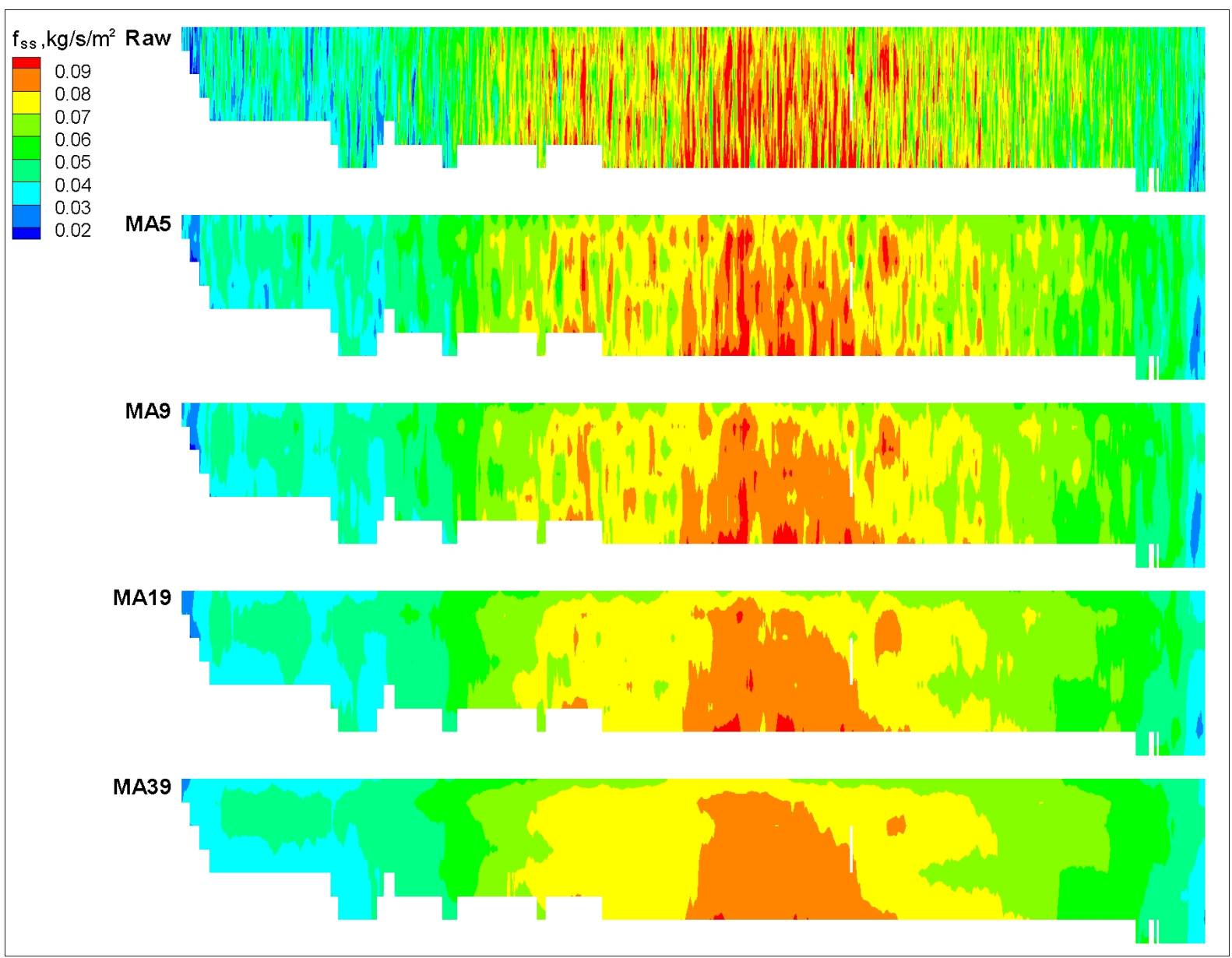

Fig. 9. Cross-sectional distribution of sediment flux (MA indicates moving average window size).
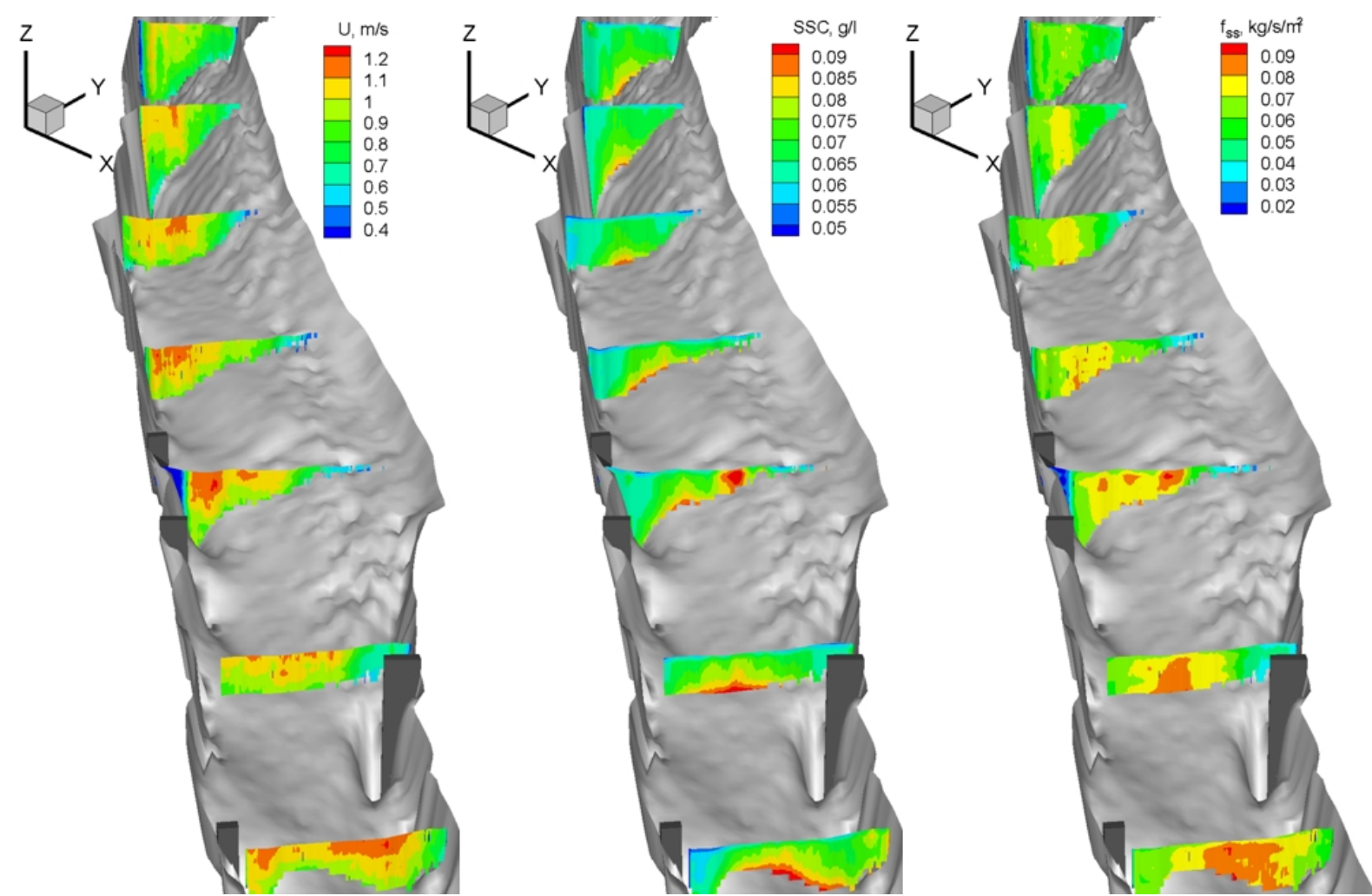

Fig. 10. Spatial distribution of a) flow velocity, b) SSC and c) sediment flux (flow direction from top to bottom). 
sensitive to the smoothing of raw EI data. As a result of the moving ADCP data post-processing the spatial distributions of SSC and the sediment load distribution could be assessed for the whole study reach (Fig. 10).

Despite that the introduced method is calibrated against detailed field measurements, there might be several limitations which have to be considered in future research. First, the effect of grain size distribution on the backscattered power should be taken into account, which was neglected here due to the well sorted grains. An attempt on quantifying the grain size distribution with multi-frequency methods using several ADCPs was introduced by Guerrero et al. (2011). They found acceptable agreements between the methods compared to each other, however, besides the three different ADCPs they performed depthintegrated sediment sampling, which resulted in some implications on spatial and time alignments between sampling and ADCP surveys. Second, measurement uncertainty near the river bed and the lack of ADCP data near the free surface can have significant effect on the suspended sediment load estimations, as was shown here. Some attempts on using upward-looking ADCP (Wall et al., 2006) or side-looking ADCPs, located close to the river bed, might provide more accurate data in these zones. Third, the error of SSC estimation can increase as the particle circumference approaches the acoustic wavelength. In our case, however, the acoustic wavelength was much higher, thus decreased this phenomenon, nevertheless, it has to be always verified. In addition, it is to note that the introduced method is instrument and site specific, furthermore, it also depends on the measurement circumstances. Hence, a generalized relationship between the relative backscatter and SSC cannot be established. Therefore, it is crucial to perform simultaneous sediment sampling when carrying out ADCP backscatter analysis. However, the quality of concurrent suspended sediment sampling results is also questionable which has to be considered. It could be a topic of future researches how the inaccurate $S S C$ data, as the input for the method introduced in this paper, affects the reliability of the estimation process.

An ADCP-based reliable method to estimate SSC can lead to a more detailed knowledge of sediment regime both in space and time. Such a measurement method can obviously support the study of complex hydrodynamic situations and related sediment transport phenomena. We believe that the method presented here can significantly contribute to river monitoring and engineering activities as well as to the calibration of laboratory and CFD models.

\section{REFERENCES}

Deines, K.L., 1999. Backscatter estimation using broadband acoustic Doppler current profilers. Proceedings of the IEEE Sixth Working Conference on Current Measurement, San Diego, CA, March 11-13, 1999, 249-253.

DRL Software Ltd, 2003. DRL-Sediview software user manual V3, DRL Software Ltd.
Downing, A., Thorne, P.D., Vincent, C.E., 1995. Backscattering from a suspension in the near field of a piston transducer. Journal of the Acoustical Society of America, 97, 1614-1920 .

Gartner, J.W., 2004. Estimating suspended solids concentrations from backscatter intensity measured by acoustic Doppler current profiler in San Francisco Bay, California. Marine Geology, 211, 169-187.

Guerrero, M., Szupiany, R.N., Amsler, M., 2011. Comparison of acoustic backscattering techniques for suspended sediments investigation. Flow Measurement and Instrumentation, 22, 5, 392-401.

Guerrero, M., Rüther, N., Szupiany, R.N., 2012. Laboratory validation of acoustic Doppler current profiler (ADCP) techniques for suspended sediment investigations. Flow Measurement and Instrumentation, 23, 1, 40-48.

Kim, Y.H., Voulgaris, G., 2003. Estimation of suspended sediment concentration in estuarine environments using acoustic backscatter from an ADCP. In: Proceedings of the International Conference on Coastal Sediments (Clearwater Beach, Florida, USA).

Kostaschuk, R., Best, J., Villard, P., Peakall, J., Franklin, M., 2005. Measuring flow velocity and sediment transport with an acoustic Doppler current profiler. Geomorphology, 68, 25-37.

Reichel, G., Nachtnebel, H.P., 1994. Suspended sediment monitoring in a fluvial environment: advantages and limitations applying an acoustic Doppler current profiler. Water Resources Research, 28, 4, 751-761.

Schulkin, M., Marsh, H.W., 1962. Sound absorption in sea water. Journal of the Acoustical Society of America, 34(6), 864-865.

Tamás, E., Baranya, S., 2008. SEDIBAL - Sediment Balance for the Danube River. Interim Report. Hungary. UNESCO/Universität für Bodenkultur Wien.

Thevenot, M.M., Prickett, T.L., Kraus, N.C. 1992. Tylers Beach, Virginia, dredged material plume monitoring project 27 September to 4 October 1991. Dredging Research Program Technical Report DRP-92-7, US Army Corps of Engineers, Washington, DC, pp. 204.

Urick, R.J., 1948. The absorption of sound in suspensions of irregular particles. Journal of the Acoustical Society of America, 20(3), 283-289.

Urick, R.J., 1983. Principles of Underwater Sound. McGraw Hill, New York, pp. 384.

Wall, G.R., Nystrom, E.A., Litten, S., 2006. Use of an ADCP to compute suspended-sediment discharge in the tidal Hudson River, New York. US Geological Survey Scientific Investigations Report., Tech rep., US Geological Survey.

Received 1 April 2012 Accepted 6 December 2012 